\title{
Business management method based on human capital network model
}

\author{
Lin Du, Yang Song \\ Xi'an University Of Architecture And Technology, Shannxi 710055, China;
}

Keywords: Human capital network, node, influence, team science initiatives.

\begin{abstract}
Human Resource has become more and more important in a large-scale enterprise with hierarchy organization structure. For a company, the momentous task of human resource is achieving an ideal allocation of human resources among levels to produce the greatest benefits in the development of the enterprise. In this paper, a network model of human capital is established based on a company with 58 departments. Each department is a node of the network, and at the same time these nodes connect different weight lines. Through simulation, the influence of each level position to other departments can be obtained. Finally, according to the team science initiatives, some valuable suggestions for HR were put forward.
\end{abstract}

\section{Introduction}

With the rapidly of market economy, and the advent of the era of knowledge economy, building an organization filled with good, talented, well-trained people is one of the keys to success. Everybody plays unique roles within their organizations; therefore, human capital is the core of organization survival and the innovation development support. It is no denying that the built organization can used in many fields, such as enterprise, education etc.

Human resource(HR) often help senior leader to manage personnel by coordinating training, and improving retention. In fact, HR seek a effective organization structure, where individuals can be assigned to positions appropriate to their talents and experiences, and where efficient communication systems are in place to facilitate development and quality products.

\section{Data analysis}

Fig. 1 shows the ICM company has 370 total employees who organized in forty-six divisions of seven people and twelve offices of four people. For a HR manager, it is not realistic to know each employee, due to this large number of employees and frequently employee departure and entrance. But, the HR manager assumes that he knows all the details of each department or office. This detail include the number of people, each people level (given in Table 1), division or office level in Fig.1. A division or office is seemed as a unit is reasonable. Fig. 1 gives a tree structure with five levels. The structure level regard as the division or office level in ICM company in our work. 


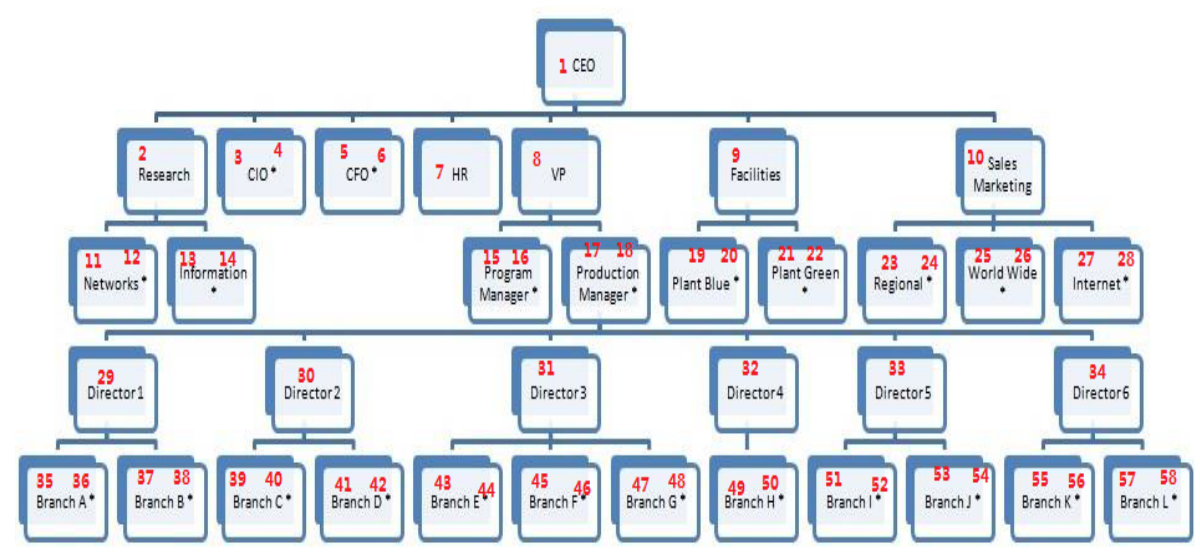

Figure 1 company structure.

In the tree structure of Fig.1, each division or office is seemed as a node and each link is seeming as a edge. Total fifty-eight divisions and office are draw out from Fig.1. For each division or office, the number of people, each staff member level, division or office level should be added on our model.

In the network, a node presents a division/office, attached a vector of seven components and a integer value. The vector denotes the staff situation in the division/office. For example, the vector $\left(a_{1}, a_{2}, \cdots, a_{7}\right)$ attached a node. It should satisfy $a_{1} \geq a_{2} \geq \cdots \geq a_{7} \geq 0$. The situation of $a_{5}=0$ means four people in this office, otherwise seven people in this division, and people's levels are $a_{1}, a_{2}, \cdots, a_{7}$,respectively. The integer value denotes the division/office level in Fig.1. Besides, a edge presents link relationship between 2 divisions/office. The weight attached on an edge presents the strength of the link. In the tree structure of Fig.1, all edges remain. Between arbitrary 2 nodes in same level, a edge is added. if these 2 nodes have same direct parent node, a higher weight $\alpha$ is attached on the edge, otherwise a lower weight $\beta$ attached.

\section{Human Capital network model}

Fig. 1 has one division/office in 1th level, seven divisions/offices in second level, etc. Table 1 has ten employees on the highest level (Senior manager/Executive), twenty employees on the second level, etc. So, we can't think same level divisions have same staff especially in staff member levels. To assign values on our model, we have to assign levels for every staff member in each division/office on the basis of our assumptions.

\subsection{Algorithm 1: Assignment attribute values}

According to the list of Level of Position and Number of Employees at this level on Table 1, correspondingly allocate staff's ability and number for each position, such as arranging four Senior Manager in the CEO (This is based on the properties of CEO itself, because the CEO in the company plays the role on decision-making of major project, guiding the development direction of the company, etc, so as the CEO the man's ability must be strong.)

Note: (1)We have to sort the Ability Value of 370 staff members mentioned in assumptions. We can know that the first one is the best, and the 370th is the last.

(2)The allocation of personnel should combine the Figure1's tree diagram.

(3)In the tree diagram, CIO and CFO had a “*”, so there are two divisions respectively in CIO and Coteach division has seven people.

\subsection{Algorithm 2: Assignment weights}

The connections between nodes attach effect between nodes, for example, the relationship between nodes of CEO and Clothe weight value of the changes in the CEO effect on CIO is 1, effects of CIO changes on CEO is 0.6, this is because the top leadership will have a great influence. 
On his management staff in the lower trust, cooperation, but the lower staff will not be particularly large impacting on the leadership.

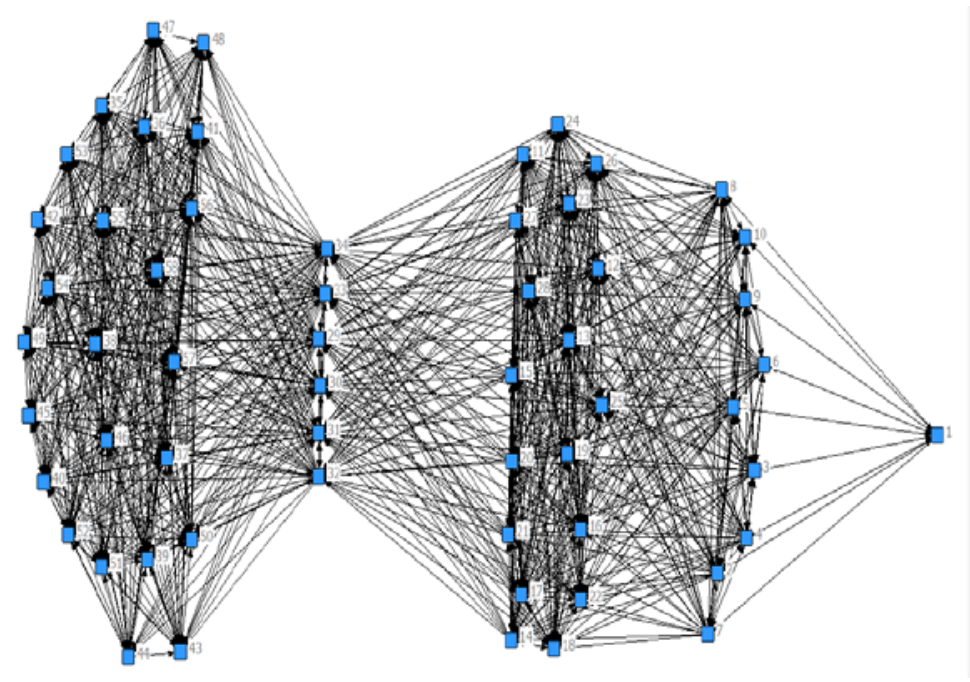

Figure 2 Human Capital Network of 58 Divisions.

This model identifies dynamic processes within the Human Capital network. Dynamic processes involved in organizational churn and direct/indirect effects on the organization's productivity. Individual will change accordingly when the organization generates a churn the company's productivity will have an effect. Therefore, I define the importance and influence firstly for the organization. Then making a decision for the definition of churn. Next, 370 people are regarded as the node, namely 58 nodes (divisions).

Determinants of the importance has two, one is the node number of layers in the system, the second is the number of branches of the node.

$\mathrm{Im}=\mathrm{N}^{*} \mathrm{a}$

( $\mathrm{N}$ is the floors of node, a is the number of the node's branch)

The influence is that the role of the different levels within the division's position has effect on division.

In $=\mathrm{e}^{*} \mathrm{Co}$

e is the influence for itself.

$$
\varepsilon=\frac{\psi}{(\mathrm{n}(\mathrm{low}) * 3+\mathrm{n}(\mathrm{mid}) * 6+\mathrm{n}(\text { high } * 9))}
$$

$\mathrm{Y}$ is the value of this position. ( $\mathrm{y}_{\text {high }}=9$, ymid $=6, \mathrm{y}_{\text {low }}=3$ )

There are three network nodes (division) in the figure 1 . The division one has three levels of position $\mathrm{H}, \mathrm{M}$ and $\mathrm{U}$, the division two and three has two levels of position $\mathrm{H}, \mathrm{M}$. When personnel in division one churn, then the impact on the other divisions which connect with division one will be influenced. From the above definition, the influence from Sector one to Sector two is In=y1*Co13. Similarly, the influence from Sector two to Sector three is In=y1*Co12. Followed by analogy, the influence can be obtained in the other two level of individuals to other divisions.

Similarly, we can use this model to get influence of the entire network 58 divisions in each level position after being churned. By analysising the process and definitions of the above, the dynamic process is simulated by MATLAB. For different levels in different divisions churns, you can get its influence on the other 57 divisions.

They are a typical random process. The influence of the system in the next stage (after the current state of the future) only relates to this stage at present. They have nothing to do with the system before the state. This progress can be described as follows: 


$$
\begin{aligned}
& P\left(Y_{n+1}=y_{n+1} \mid Y_{0}=y, Y_{1}=y_{1}, \ldots, Y_{n}=y_{n}\right)=P\left(Y_{n+1}=y_{n+1} \mid Y_{n}=y_{n}\right) \\
& P(n)=\left[\begin{array}{ccccc}
p_{11}(n) & p_{12}(n) & \cdots & p_{158}(n) \\
p_{2}{ }_{1}(n) & p_{22}(n) & \cdots & p_{28}(n) \\
\vdots & \vdots & \cdots & \vdots \\
p_{58}{ }_{1}(n) & p_{58}{ }_{2}(n) & \cdots & p_{58}(n)
\end{array}\right] \\
& 0 \leq p_{i}{ }_{j}(n) \leq 1
\end{aligned}
$$

The random variable $X_{n}$ in $\left\{X_{n}=x_{n}, i=0,1,2 \cdots\right\}$ shows that the variable in the $n$ times churn affect the influence of values. $P(n)$ expresses the influence between departments in the $n$ times churn.

\section{Results conclusion}

From the data of company, the eight division has three levels positions, that is, levels 1, 2, 3 . When the $\mathrm{H}$ level (is level 1) of eight division has churned, I get the influence of other sectors from the simulation.
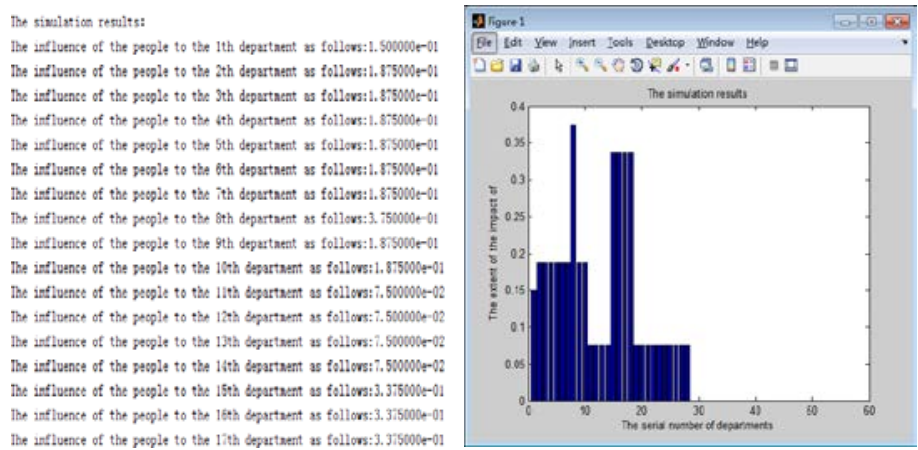

Figure 3 Influence for eight division.

What's more, the thirty-two division has two levels positions, that is, levels 5 , 6 . When the $\mathrm{M}$ level (is level 6) of thirty-two division has churned, I get the influence of other sectors from the simulation.


Figure 4 Influence for thirty-two division.

Team science initiatives are designed to promote collaborative, and often cross-disciplinary (which includes multi-, inter-, and transdisciplinary) approaches to answering research questions about phenomena. The HR manager's vision is that the HR office should take the lead in this effort to connect the network models of the organization. How this could happen? The human resources department may need to do the following:

Firstly, suggest each high manage division to make a network about their work, all networks have same vertex set as same as the Human Capital have. Secondly, assemble those networks into a multilayer network(Fig.10) This multilayer network has one aspect and many layers. such as Human Capital Layer, Information Flow layer, Production Manage and Control layer, Friendship layer, etc. Thirdly, use the multilayer network to promote collaborations, improve productive 
efficiency. This multilayer network facilitates information share, good communication, prevent and manage disputes and conflicts, etc.

\section{References}

[1]. Branco, M.C., Xiong, Y., Czarnecki, K. et. A case study on consistency management of business and IT process models in banking[J].2014(13): 913.

[2]. Zoet, M. \& Versendaal, J. Defining collaborative business rules management solutions: framework and method[J]. Inf Syst E-Bus Manage.2014(12): 543.

[3]. Nelson ML, Peterson J, Rariden RL, Sen R. Transitioning to a business rule management service model[J] case studies from the property and casualty insurance industry.2010, 47(1):30-41

[4]. Birley, S. The role of networks in the entrepreneurial process. Journal of Business Venturing, 1985(1): 107-117.

[5]. Maroukian, K., Apostol Poulos, C. \& Tsaramirsis, Extending model driven engineering aspects to business engineering domain: a model driven business engineering approach[J]. G. Int. j. inf. tecnol. 2017(9): 49.

[6]. Chang, JF. \& Huang, YM. PSO based time series models applied in exchange rate forecasting for business performance management[J]. Electron Commer Res (2014) 14: 417.

[7]. Santarelli, E. \& Tran, H.T. The interplay of human and social capital in shaping entrepreneurial performance: the case of Vietnam[J]. Small Bus Econ .2013(40) : 435. 